\title{
Distributed TLDs in RC floors and their vibration reduction efficiency
}

\author{
Ye Lieping (叶列平 $)^{1 \dagger}$, Lu Xinzheng (陆新征 $)^{1 \uparrow}$, Qu Zhe (曲 哲) $)^{1 \S}$ and Hou Jianqun (侯建群 $)^{2 *}$ \\ 1. Key Laboratory of Structural Engineering and Vibration of China Education Ministry, Department of Civil Engineering, \\ Tsinghua University, Beijing 100084, China \\ 2. Tsinghua Institute of Architectural Design, Beijing 100084, China
}

\begin{abstract}
A novel distributed tuned liquid damper (DTLD) for reducing vibration in structures is proposed in this paper. The basic working principle of the DTLDs is to fill the empty space inside the pipes or boxes of cast-in-situ hollow reinforced concrete (RC) floor slabs with water or other liquid. The pipes or boxes then work as a series of small TLDs inside the structure, to increase the damping ratio of the entire structural system. Numerical simulation that accounts for the fluidstructure coupling effect is carried out to evaluate the vibration-reduction efficiency of the DTLDs. The results show that the DTLDs are able to considerably increase the damping of the structure and thus reduce its vibration. An additional benefit is that the DTLDs do not require architectural space to be added to the structure.
\end{abstract}

Keywords: distributed tuned liquid damper(DTLD); fluid-structure interaction(FSI); vibration reduction; hollow floor slab

\section{Introduction}

Tuned liquid dampers (TLD) have been widely used to control vibration in structures (Li et al., 2005). In structures with cubic box, cylinder or U-shape tube configurations, a common installation pattern is to concentrate one or several TLDs on specifically-selected floors.

Existing research and applications indicate that TLDs offer acceptable performance at a reasonable cost (Qian et al., 1998; Jia et al., 2000; Jia et al., 2002). However, their application is limited due to the following drawbacks:

(1) Smaller TLDs with less total mass cannot successfully meet the demands of vibration reduction, while larger TLDs need a large architectural space. This places a significant burden on the structure to support them, and increases the cost of implementation.

(2) The natural frequency of the TLD needs to be tuned to be close to that of the structure in order to achieve efficient vibration control (Jia et al., 2006).

\footnotetext{
Correspondence to: Ye Lieping, Key Laboratory of Structural Engineering and Vibration of China Education Ministry, Department of Civil Engineering, Tsinghua University, Beijing 100084, China

Tel:86-10-62795330

E-mail: ylp@tsinghua.edu.cn
}

${ }^{\dagger}$ Profess; ${ }^{\ddagger}$ Associate Profess; ${ }^{\S}$ Ph.D.; ; Senior Engineer

Supported by: Cultivation Fund of the Key Grant Scientific and Technical Innovation Project, Ministry of Education of China Under Grant No.704003

Received July 1, 2007; Accepted August 30, 2007
However, it is often difficult to accurately estimate the natural frequency of the structure. Furthermore, the natural frequency can change during the service life of the structure.

In recent years, cast-in-situ hollow floor slabs became popular in construction due to their light-weight, noise insulation and good structural properties (Xu and Feng, 2005). PVC or rubber tubes or boxes are commonly used and are also good liquid containers.

Filling the spaces inside the hollow floor slabs with water or other damping liquid turns the floor into a distributed TLD (DTLD) system (see Fig. 1), which considerably increases the damping of the structure. The advantages of DTLDs are as follows.

(1) Setup flexibility. The hollow volume ratio of modern hollow floor slabs can be up to $66 \%-75 \%$ or more, which provides enough space to set up the DTLDs. With a relatively large total mass of TLDs, the damping capability of the structure increases. Moreover, these TLDs can also be embedded into huge girders or columns in some high-rise structures and thus further increase the damping.

(2) No extra architectural space is needed to accommodate the TLDs and their distributed mass allows for a higher structural loading capacity when compared to traditional concentrated TLDs.

(3) Wide variable frequency range. As opposed to traditional TLDs, which provide a kinematic reaction force while the structure oscillates, the DTLDs increase the damping of the entire structure and decrease its overall response. As a result, the DTLDs are not as sensitive 


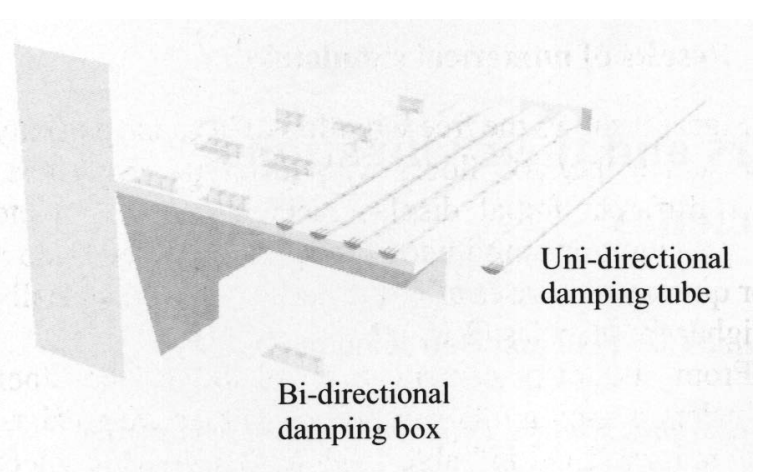

Fig. 1 DTLDs in a hollow floor slab

as TLDs to the natural frequencies of the structure.

(4) Construction is simple, since almost the same procedures as for normal hollow floors can be followed. Furthermore, there is no extra cost.

(5) Fire resistance is enhanced if the water inside the floor slabs can be used to put out a fire.

The purpose of this paper is to verify the concept of DTLDs and theoretically prove their feasibility by numerical simulation that considers the fluid-structure interaction (FSI). An experimental study is being conducted to evaluate the vibration reduction efficiency of these DTLDs.

\section{Fluid-structure interaction(FSI) simulation}

In structures with TLDs installed, vibration causes the liquid in the TLDs to slosh, which consumes energy and imposes a reaction force on the structure. Different structural vibrations cause different rates of liquid sloshing and thus exercise a different influence over the structure. Over the past few decades, many simplified models to implement TLDs in structural analysis have been proposed. In these models, the TLD is often modeled as a concentrated equivalent mass with elastic springs and viscous dampers, which provide control forces over the structure (Housner, 1957; Jia and Li, 1998; Cai et al., 1998). In recent years, with the development of computational mechanics as well as the hardware and software environment, FSI-based analysis has become a practical numerical simulation method for structures with TLDs. In FSI simulation, the following three aspects are important (Wu and Shen, 2003). ible.

(1) Liquid domain: liquid is treated as incompress-

(2) Solid domain: material and geometric nonlinearities are considered.

(3) Fluid-solid interface: The fluid-solid interface is the key in FSI simulation because different formulations are commonly adopted for liquids and solids. The Euler formulation is used for liquids while the Lagrange formulation is used for solids. Arbitrary LagrangianEulerian (ALE) formulation is often used to solve such problems (Yue et al., 2000).

The analysis is conducted in the following steps:

(1) Determine the liquid pressure imposed on the surface of the structure by taking the undeformed structure as the liquid boundary and calculating the liquid field.

(2) Apply the force to the structure and modify the liquid boundary and mesh according to its deformation, and then recalculate the liquid pressure.

(3) Repeat steps (1) and (2) until the difference in liquid pressures obtained in two successive calculations becomes smaller than the tolerance level.

A detailed discussion on conducting FSI simulation based on ANSYS can be found in Lu et al.(2005) and its feasibility has been proven. A similar numerical simulation approach is used in this paper to evaluate the vibration-reduction efficiency of DTLDs. The FSI capacity of ANSYS, as well as the free surface fluid model simulation capacity of the Volume of Fluid (VOF), has been adopted in many applications in industry and academic areas, and its reliability has been well established (Gohner and Mauch, 1998; Haque et al., 2006). The numerical simulation with FSI and VOF in the present study has been benchmarked using the widely accepted case carried out by Hirt and Nichols (1981). Hence, the simulation results are both feasible and reliable.

\section{Vibration-reduction efficiency of a single TLD}

\subsection{Realistic model}

Figure 2 shows a simplified model of a hollow floor slab with a height of $250 \mathrm{~mm}$ containing a TLD with a height of $150 \mathrm{~mm}$. The hollow volume ratio and the slab height fulfill the requirements specified in Chinese specifications (CECS, 2004). The water depth is $2 / 3$ of the hollow height (i.e., $100 \mathrm{~mm}$ ) and the overall water mass ratio is $31 \%$. The stiffness of the structure is represented by a horizontal spring and the bottom of the slab can slide freely in the horizontal direction. In the analysis, the slab is pulled out against the spring to a certain distance and suddenly released to make it vibrate naturally. The damping of this system and the vibration-efficiency of the TLD is obtained by examining the decline of the vibrating amplitude.

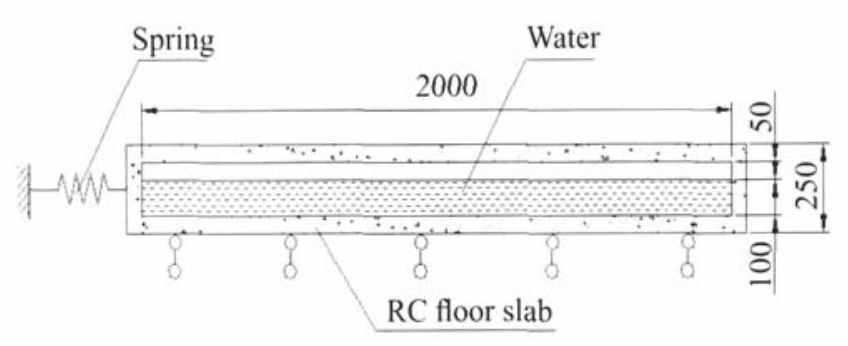

Fig. 2 Simplified unit of cast-in-situ hollow RC floor with TLD (length unit: $\mathrm{mm}$ ) 


\subsection{Numerical model}

A one-meter wide hollow floor shown in Fig. 2 is simulated as a 2D numerical model in ANSYS. The liquid is modeled by a VOF technique implemented in ANSYS, which is capable of modeling the liquid surface vibration and the change in liquid height, and can also transfer the liquid pressure to the structure. Water is used for the TLD liquid with a density of $1000 \mathrm{~kg} / \mathrm{m}^{3}$ and a kinematic viscosity of $1 \times 10^{-6} \mathrm{~m}^{2} / \mathrm{s}$. The container walls are modeled by beam elements. The fluid-solid interface is arranged between the container walls and liquid elements. The natural frequency of the structure is adjusted by changing the spring stiffness. Initial displacements of $0.01 \mathrm{~m}$ and $0.05 \mathrm{~m}$ are imposed on the floor slab in two different cases, respectively. To improve the numerical convergence, a $1 \%$ initial damping is assigned to the

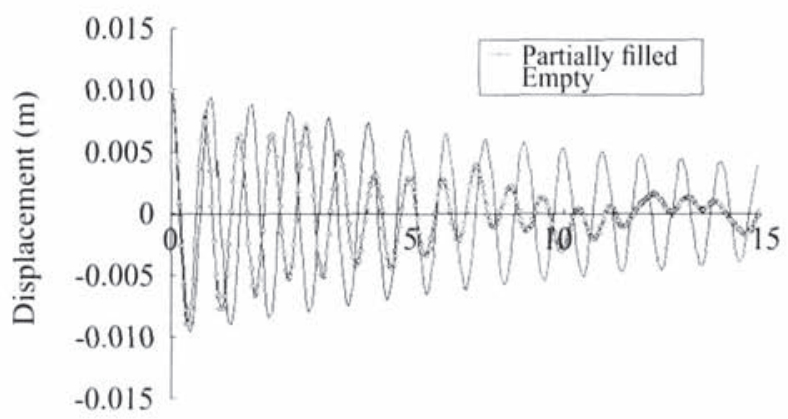

Time (s)

(a) Natural freq. $=1 \mathrm{~Hz}$, Max amplitude $=0.01 \mathrm{~m}$

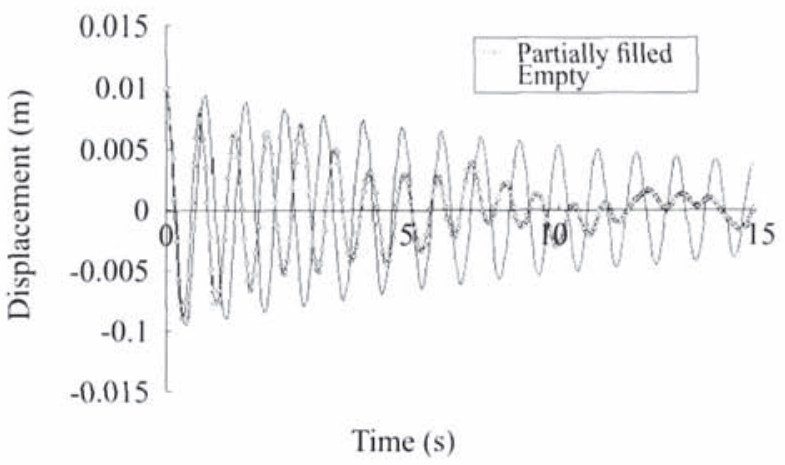

(c) Natural freq. $=1 \mathrm{~Hz}$, Max amplitude $=0.05 \mathrm{~m}$ structure.

\subsection{Results of numerical simulation}

Figure 3 shows the free vibration of both the partially filled and empty RC floors with different frequencies under different initial displacement excitations. Note that the vibration amplitude of the partially filled hollow floor quickly decreases after the earlier stage, especially in higher frequencies $(2 \mathrm{~Hz})$.

From the displacement time histories, the floor equivalent damping ratios in different cases were calculated and are listed in Table 1. Note that the equivalent damping ratio increases from the initial value of $1 \%$ to $2.4 \%-2.8 \%$. This increase in the equivalent damping ratio is explained as the energy-dissipation of the sloshing water (Fig. 4) due to the water viscosity.

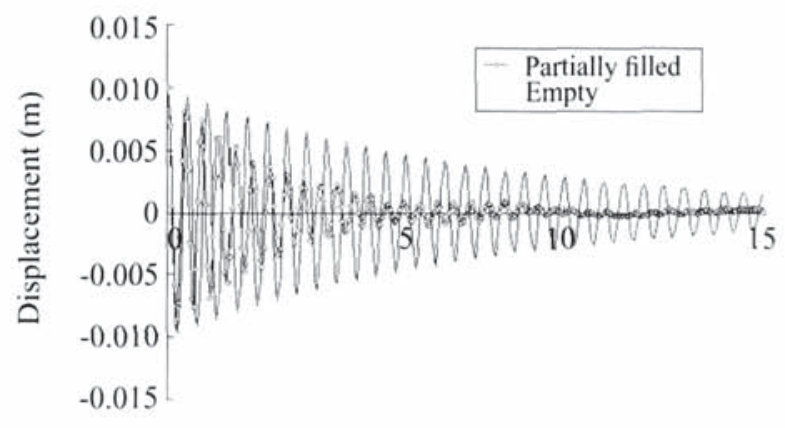

Time (s)

(b) Natural freq. $=2 \mathrm{~Hz}$, Max amplitude $=0.01 \mathrm{~m}$

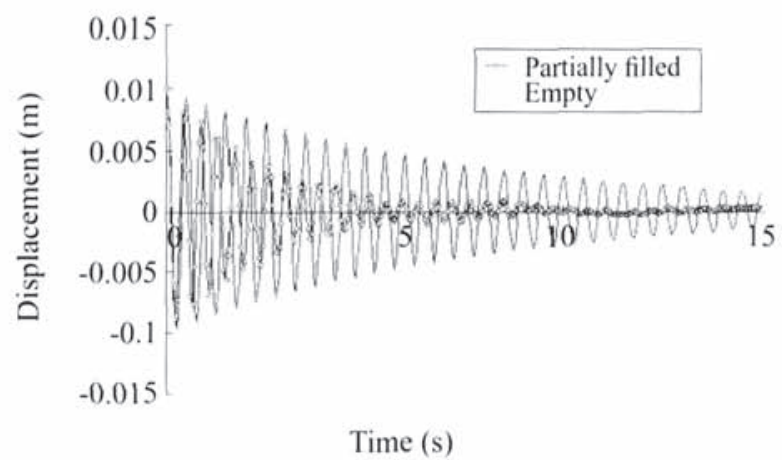

(d) Natural freq. $=2 \mathrm{~Hz}$, Max amplitude $=0.05 \mathrm{~m}$

Fig. 3 Vibration reduction of single TLD

Table 1 Changes of equivalent damping ratio of TLD system

\begin{tabular}{clc}
\hline & Cases & $\begin{array}{c}\text { Eq. damping ratio } \\
(\%)\end{array}$ \\
\hline \multicolumn{1}{c}{ Empty } & 1.00 \\
\multirow{2}{*}{ Part. $\quad$ Natural freq. $=2 \mathrm{~Hz}$, Max ampl. $=0.01 \mathrm{~m}$} & 2.83 \\
filled & Natural freq. $=1 \mathrm{~Hz}$, Max ampl. $=0.05 \mathrm{~m}$ & 2.64 \\
& Natural freq. $=2 \mathrm{~Hz}$, Max ampl. $=0.05 \mathrm{~m}$ & 2.69 \\
\hline
\end{tabular}




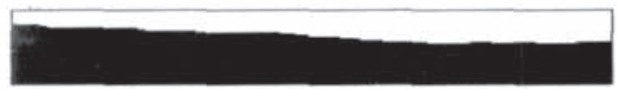

(a) $t=9.7 \mathrm{~s}$

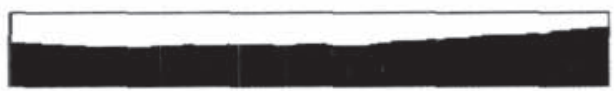

(b) $t=10.0 \mathrm{~s}$

Fig. 4 Vibration of the liquid free surface (Natural freq. $=1 \mathrm{~Hz}$, Max amplitude $=0.05 \mathrm{~m}$ )

\section{Vibration-reduction efficiency of DTLDs}

\subsection{Numerical model}

Figure 5 shows a four-story steel frame with cast-insitu hollow floors. Its first natural frequency is $1.78 \mathrm{~Hz}$ and its initial damping is taken as $1 \%$. The heights of the overall RC slab and the hollow space are $250 \mathrm{~mm}$ and $150 \mathrm{~mm}$, respectively. The El-Centro earthquake record is input at the bottom of the structure. The following parameters are adopted in the simulation.

(1) Mesh size. It is well-known that the result of a finite element analysis is closely related to the mesh size used. To verify the mesh convergence, two element sizes, i.e., $3 \mathrm{~mm}$ and $5 \mathrm{~mm}$ in the liquid domain, are adopted.

(2) Liquid depth. Three cases with different liquid depths (empty, $75 \mathrm{~mm}$ and $100 \mathrm{~mm}$ ) are considered.

(3) Length of hollow space. The length of a single liquid container changes from $2 \mathrm{~m}$ to $4 \mathrm{~m}$.

The weight of the RC floor slabs is also adjusted to keep the overall weight of the structure constant.

\subsection{Results and discussions}

Figure 6 shows that the mesh size in the liquid domain had only a minor impact on the simulation results. Therefore, in the following simulations, the liquid element size of $5 \mathrm{~mm}$ is used to save computational time.

Figure 7 shows that a larger container length (4 m) yields a larger amplitude reduction. Some important sta-

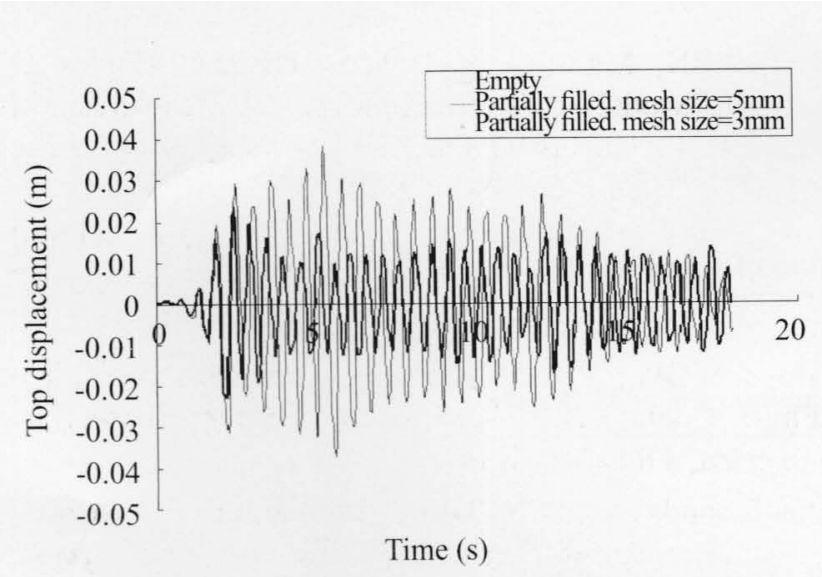

(a) $L=2 \mathrm{~m}$ tistical results of the maximum displacement response are shown and compared in Fig. 8. The figure shows that the higher container length $(L=4 \mathrm{~m})$ at a liquid depth of $75 \mathrm{~mm}$ yields less displacement, as indicated above, but at a larger liquid depth $d=100 \mathrm{~mm}$, the higher container length $(4 \mathrm{~m})$ yields a larger displacement. However, in general, the displacement response of the structure decreases by $30 \%$ regardless of the maximum displacement or displacement variance. This is equivalent to an increase in the damping ratio of the structure from $1 \%$ to $3 \%-5 \%$.

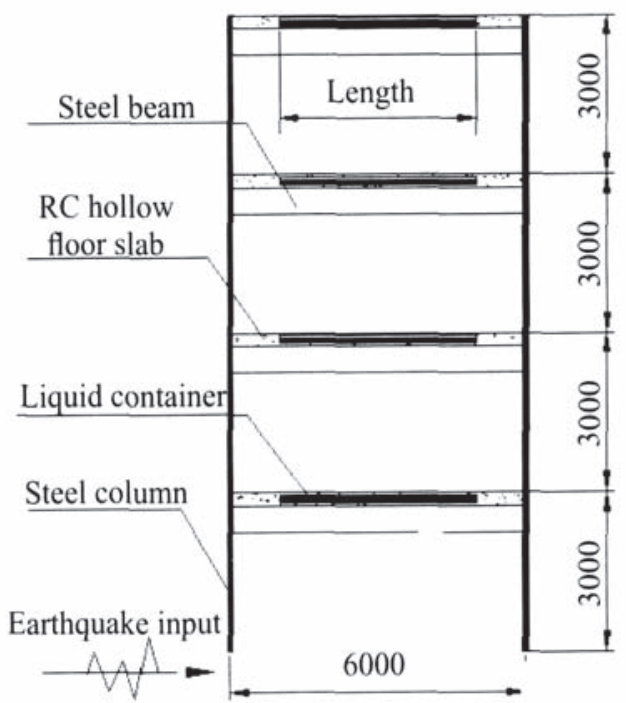

Fig. 5 Model of a simple steel frame (Length unit:mm) )

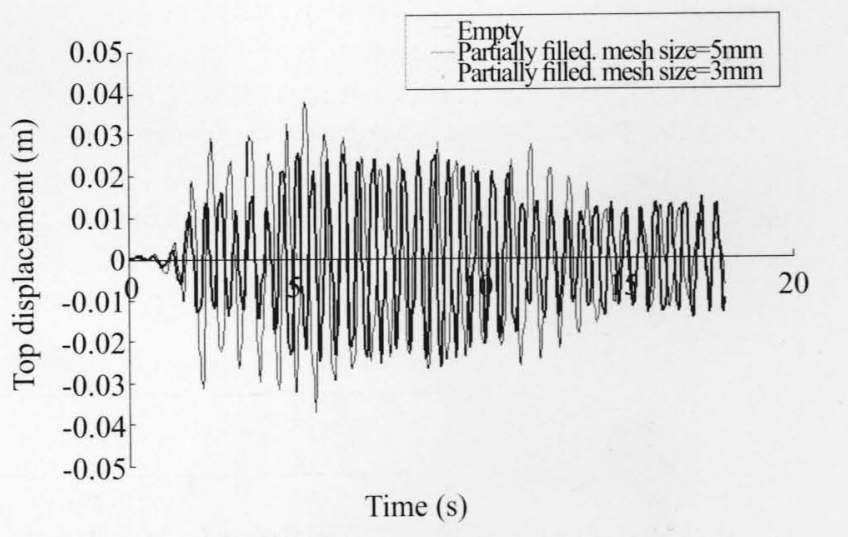

(b) $L=4 \mathrm{~m}$

Fig. 6 Effect of mesh size for different container length (liquid depth $=100 \mathrm{~mm}$ ) 


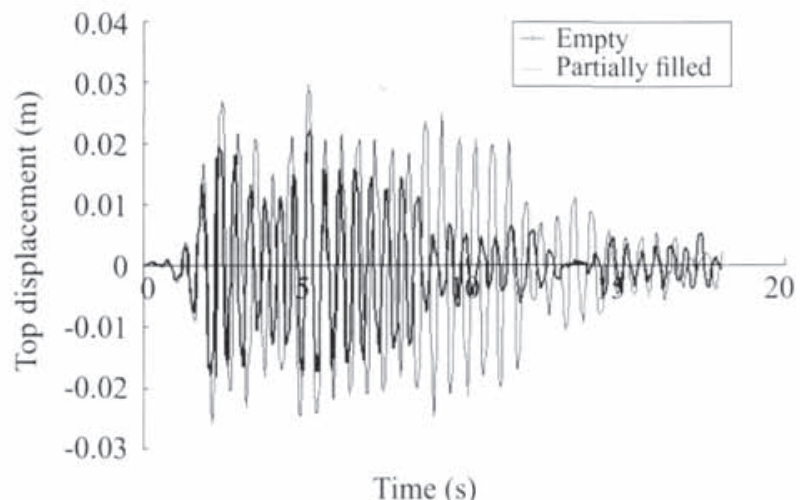

(a) $L=2 \mathrm{~m}$

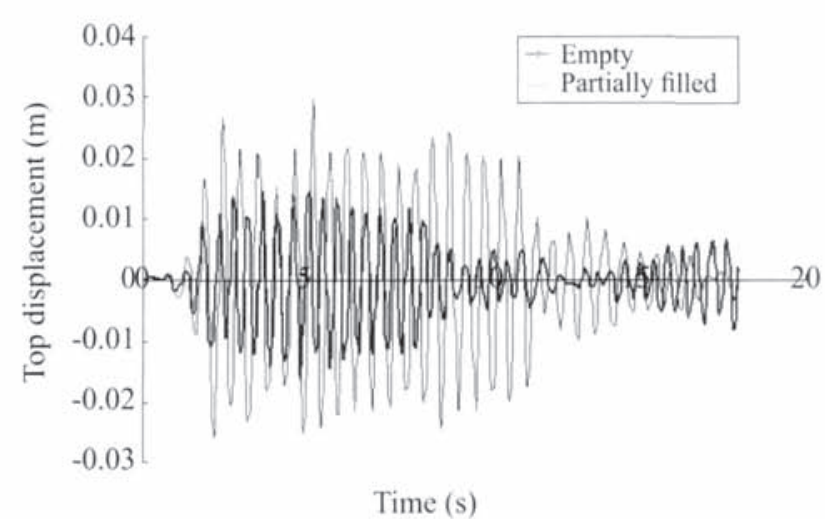

(b) $L=4 \mathrm{~m}$

Fig. 7 Comparison of container length influence (liquid depth $d=75 \mathrm{~mm}$ )

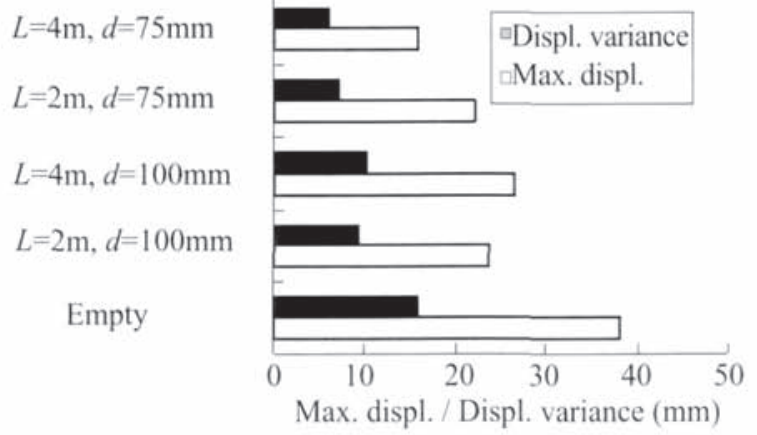

(a) Maximal displacement response under earthquake

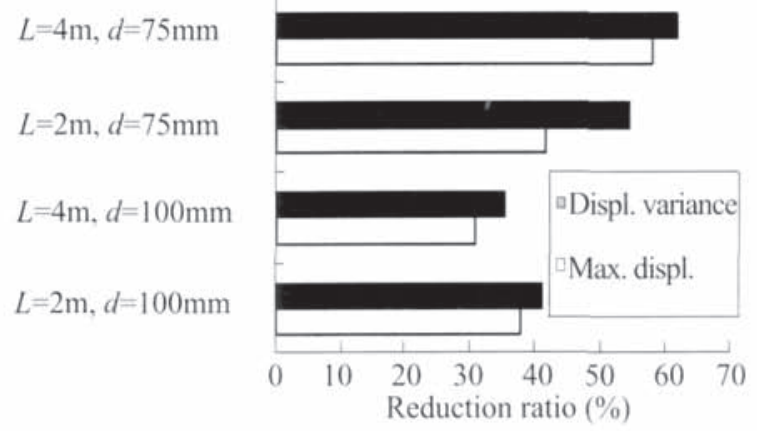

(b) Comparison of vibration-reduction effects

Fig. 8 Statistical results of vibration reductions

\section{Conclusions}

Distributed tuned liquid dampers (DTLDs), created by filling cast-in-situ hollow floor slabs with liquid, are proposed in this paper to reduce vibration in a structure. FSI simulation based on ANSYS has been carried out to prove both the efficiency and feasibility of the DTLDs. The results show that DTLDs can considerably increase the damping of the structure, and thus reduce its vibration with relatively low additional cost. And, the DTLDs do not occupy any additional architectural space.

Further research on the influence of several factors, such as the optimal amount of liquid, the positions and arrangement of DTLDs in the structural system, and the inner configuration of the liquid container, is being conducted.

\section{References}

Cai DY, Li AQ and Cheng WR (1998), "Study on Equivalent Mechanical Model of Tuned Liquid Damper," Earthquake Engineering and Engineering Vibration, 18(1): 80-87. (in Chinese)
CECS 175 (2004), Technical Specification for Castin-situ Concrete Hollow Floor System, Beijing. (in Chinese).

Gohner U and Mauch H (1998), “FLOTRAN: Numerical Method and Industrial, Applications,” International Journal of Computer Applications in Technology, 11(35): 199-202.

Haque JN, Mahmud T, Roberts KJ and Rhodes D (2006), "Modeling Turbulent Flows with Free-surface in Unbaffled Agitated Vessels,” Industrial \& Engineering Chemistry Research, 45(8): 2881-2891.

Hirt CW and Nichols BD (1981), "Volume of Fluid (VOF) Method for the Dynamics of Free Boundaries," Journal of Computational Physics, 39: 201-225.

Housner GW (1957), "Dynamic Pressure on Accelerated Fluid Containers,” Bulletin of Seismic Society of America, 47(1):15-35.

Jia Y and Li HN (1998), "Simulation of Dynamic Liquid Pressure for Tuned Liquid Damper," Earthquake Engineering and Engineering Vibration, 18(3): 82-87.

Jia Y, Li HN and Li YC (2000) “An Actual Computing Example for a Tall Structure Using TLD to Reduce 
Vibration," Earthquake Engineering and Engineering Vibration, 20(2): 135-140. (in Chinese)

Jia Y, Li HN and Song YS (2002) "Simplied Algorithm of Tuned Liquid Damper for Seismic Response of Fixed Offshore Platform," Earthquake Engineering and Engineering Vibration, 23(3): 160-164. (in Chinese)

Jia Y, Zhao L and Yu F (2006), "Effect of Different Parameters on TLD Vibration Control," Earthquake Engineering and Engineering Vibration, 26(4): 226230. (in Chinese)

Li HN, Jia Y, Li XG et al. (2000), "Study on Vibration Control Using TLDs for Multi-mode Reponse of tall Flexible Structures," Earthquake Engineering and Engineering Vibration, 20(2): 122-128. (in Chinese)

Li HN et al. (2005), Structure Vibration and Control, Beijing: China Architectural and Industrial Press. (in Chinese)

Lu XZ et al. (2005) "Fluid-solid Interaction Simulation on Wind Vibration of CFRP Cable," Proceedings of the $12^{\text {th }}$ National Conference of Wind Engineering, Xi'an:
69-75. (in Chinese)

Qian JR, Warnitchai P and Ding X (1998), "Shaking Table Experiment Study on the Suppression Dynamic Response of a TV Tower with TLD," Journal of Building Structures, 16(5): 31-39. (in Chinese)

Wu Y and Shen SZ (2003), "Numerical Wind Tunnel Method for Wind-vibration of Membrane Structures," Space Structure, 9(2): 38-43. (in Chinese)

Xu YL and Feng DB (2005), "Development of the Castin-situ Hollow Floor and Energy-saving RC Structures," Proceedings of the National Conference on Cast-in-situ Hollow Floor Structure, Shanghai: 1-7. (in Chinese)

Yue BZ, Liu YZ and Wang ZL (2000), "Study on Simulation and Dynamic Characters of the Nonlinear Coupling Between TLD and Structures," Journal of Vibration and Shock, 19(4): 1-4. (in Chinese)

Zheng Z, Chen F and Hou Z (2003), "Fluid-structure Interaction During Large Amplitude Sloshing and TLD Vbration Control," Tsinghua Science and Technology, 8(1): 90-96. (in Chinese) 